\title{
Closure of Cardiac Ventricle Septum
}

National Cancer Institute

\section{Source}

National Cancer Institute. Closure of Cardiac Ventricle Septum. NCI Thesaurus. Code C99940.

Repair of ventricular septum. (ACC) 